Research, part of a Special Feature on Applied Research for Enhancing Human Well-Being and Environmental Stewardship: Using Complexity Thinking in Southern Africa

\title{
Complexity of Stakeholder Interaction in Applied Research
}

\author{
Caroline Pade-Khene ${ }^{1}$, Rebecca Luton $^{2}$, Tarina Jordaan $^{3}$, Sandra Hildbrand $^{4}$, Cecile Gerwel Proches $^{4}$, Andile Sitshaluza ${ }^{5}$, \\ $\underline{\text { James Dominy }}^{6}$, Wonga Ntshinga $^{7}$ and Nosipho Moloto ${ }^{2}$
}

\begin{abstract}
Applied research in complex integrated settings should be recognized as an endeavor that requires transdisciplinary and multisectoral stakeholder interactions. The problems faced in society are quite complex, requiring participation and knowledge from diverse aspects of society, including different disciplines (academia), communities, civil society, and government. Successful applied research relies on nurturing these key stakeholder relationships and interactions. This paper explores the key challenges of stakeholder interaction in applied research in three disciplines in the South African context, based on literature and the experience of authors in their disciplines. The three disciplines include information and communication technology for development, town and regional planning, and natural resource management. We attempt to also compare and contrast these challenges across the disciplines, to identify any commonalities and differences. After considering the mutual challenges and adaptive solutions to address these challenges in the different disciplines, we identify that all three areas in relation to stakeholder interaction appear to exhibit characteristics of complex systems, hence motivating to view applied research as a complex system. In this sense, complexity theory may provide a common language between the different disciplines examining transdisciplinary stakeholder interaction in applied research from a shared perspective.
\end{abstract}

Key Words: applied research; information and communication technology for development; natural resources; stakeholder interaction; town and regional planning; transdisciplinarity

\section{INTRODUCTION AND RESEARCH PROBLEM}

Society is faced with complex problems that transcend disciplinary boundaries and require transdisciplinary and diverse stakeholder interaction to address them (Max-Neef 2005, Adam et al. 2006). Academia develops and enhances knowledge, though vital research sometimes only makes a negligible impact on society, given that key relationships and collaborations between actors or end-users in society are often nonexistent, ineffective, or even antagonistic (Brown et al. 2003, Bammer 2005, Apgar et al. 2009). Gaps exist between different disciplines, as well as academia or researchers and industry, practitioners, government and society. To address these gaps and complex problems that surround them, it is sometimes necessary for applied research to become transdisciplinary (Max-Neef 2005). Complex problems in this sense are understood by the authors to be messy interlinked problems in society, often viewed differently by different stakeholders from different disciplines and roles in society. Applied research is aimed at understanding real-world problems, with the intention of contributing to a solution that addresses the problem (Hedrick et al. 1993). This is different from basic research that focuses more on the creation of knowledge, as an end in itself, without necessarily having an immediate goal of 'addressing' a societal problem (Hedrick et al. 1993). The applied research process attempts to understand complex problems with knowledge from different disciplines, however, different stakeholders are often limited to what they 'know,' with little ability to 'understand' the problem within their constrained focus (Max-Neef 2005). Interaction between stakeholders in applied research is essential, with a focus of transcending knowledge spheres to address complex problems in society through applying transdisciplinary aspects.

Transdisciplinarity deals with the idea that social complex problems require perspectives and knowledge from diverse aspects of society, such as different research disciplines, communities, civil society, and government (Apgar et al. 2009). It is driven by three key aspects: "the need for research to be problem driven, a recognition that talking across different knowledge spheres when dealing with complex problems is necessary, and a call for participation of all groups affected" (Apgar et al. 2009:4).

Since the rise of civil society in the 1960s, the greater practice and research focus on stakeholder interaction in decision making is seen as an outcome of increased democratic thinking (Cooke and Kothari 2001, Pearce 2010). Because of the heightened global sensitivity toward democratic principles and the increasing occurrence of complex global problems, inclusionary decision making is becoming increasingly important in applied research. For applied research to be successful, nurturing key stakeholder relationships and interactions is of utmost importance. Nonetheless, a number of challenges generally exist in stakeholder interaction in applied research, such as, different intellectual and ideological frameworks, disagreement on specific goals and interests,

\footnotetext{
${ }^{1}$ Rhodes University, ${ }^{2}$ University of the Witwatersrand, ${ }^{3}$ North-West University, ${ }^{4}$ University of Kwazulu-Natal, ${ }^{5}$ University of Cape Town, ${ }^{6}$ Stellenbosch University, ${ }^{7}$ Tshwane University of Technology
} 
standards of ethical practice and accountability, power imbalances and differences, institutional structures, and marginalization of research approaches (Brown et al. 2003, Bammer 2005, Eriksson et al. 2005, Roloff 2008, Apgar et al. 2009).

Stakeholder interaction has been researched from the viewpoints that it is (i) an action (e.g., Davidoff 1965, Arnstein 1969), (ii) a process (e.g., Loh 2012), or (iii) a network or system (e.g., Booher and Innes 2002, Chettiparamb 2007). However, a more recent addition to global literature on stakeholder interaction is the possibility that it can actually rather be a complex system, to be understood from the perspective of complexity theory (e.g., Woodhill 2009).

This paper was originally developed from an academic discussion between South African researchers from three different disciplines: information and communication technology for development (ICTD), town planning (TP), and natural resource management (NRM). The discussion focused on the complexities experienced in the various disciplines when engaging with diverse stakeholders in applied research. Various similarities in experiences were identified across the three disciplines that pointed to the possibility that such experiences are not isolated within specific disciplines, but possibly reflect a broader pattern. As such, the aim of this paper is to explore the characteristics of stakeholder interaction in selected applied research in South Africa to stimulate academic discussion around the understanding of current approaches to stakeholder interaction in general.

\section{STAKEHOLDER INTERACTION IN APPLIED RESEARCH: ICTD, TP, AND NRM}

The initial exploration of stakeholder interaction in applied research should be initiated with a short introduction on stakeholder interaction in three different disciplines applied in South Africa. The three disciplines highlight key stakeholder interaction challenges faced in these essential disciplines in applied research. Our observations of these challenges are conceptually based on literature and the experience of some authors in their disciplines and research practice.

Information and communication technologies (ICTs) can broadly be defined as tools that aid in the communication between people, through means of capturing, processing, storing, and communicating information (Heeks 1999, Gerster and Zimmerman 2003). They consist of hardware and software, network appliances, radio, television, cellular phones, as well as services and applications associated with, for example, e-learning, e-health, and e-governance (USAID 2003). ICTs are key tools essential for the distribution of information and knowledge that support development activities (Moodley 2005). When these tools are seen as a component essential for contributing to economic, societal, and environmental sustainability for human well-being in developing countries, it is commonly referred to as ICT for development (ICTD; Moodley 2005). In ICTD, stakeholder interaction is required across the disciplines that support it, as well as between academia, government, private organizations, and the local marginalized community that will benefit from the initiative. It is a discipline that calls for a transdisciplinary discipline perspective because of its complex nature that requires diverse disciplines and stakeholders to collaborate effectively in understanding how best to implement and apply ICT in human development initiatives and contexts (Heeks 2009).

In town planning, stakeholder interaction generally refers to all affected individuals and parties in the planning process, each with the opportunity to influence planning decisions and outcomes (Alexander 2008). TP has a literacy tradition on stakeholder interaction almost five decades old, with some of the earlier seminal works, like that of Paul Davidoff (1965) and Sherry Arnstein (1969) still often cited. Since these works were written, a multitude of research was conducted around the concept of stakeholder interaction, culminating in variously named theories such as transactive planning (Friedmann 1973), collaborative planning (Healey 1997), and deliverative planning (Umemoto and Igarash 2009), to name a few, and an equal number of suggestions to approach stakeholder interaction in practice. What has to be accepted is that stakeholder interaction is on the increase in TP, making the discipline and its practice increasingly complex (Hillier and Healey 2008). Multiplicity in cultures, meanings, communication styles, knowledge, and development goals can be taken as a given. TP must build the theoretical basis to be able to adapt to multiplicity (Sandercock 1998, Hillier and Healey 2008). Theoretical acceptance of stakeholder interaction is a reality in TP and its concepts can be seen in practice.

South Africa's guiding legislation, such as the Development Facilitation Act (67/1995), Physical Planning Act (125/1991), and provincial legislation, like the Town-planning and Townships Ordinance (15/1991), make stakeholder interaction mandatory in most of the planning processes. However, with exception to a few standardized steps to be taken according to the legislation, how and to what depth stakeholder interaction is achieved, is only vaguely stated. This results in a situation in which the quality of stakeholder interaction for each TP project varies, based on the perspective from which the project or research is approached (Lane 2005), ranging on Arnstein's ladder of participation, from one where some stakeholders are barely involved at all (Rung 1), to one where they find little need for professional input in their planning process (Rung 8; Arnstein 1969). In South Africa, 
neither of the two extremes is advocated (Council for Scientific and Industrial Research 2000).

In a natural resource management context, research is predominantly applied in the form of management interventions, and natural scientists are increasingly acknowledging that, within a complexity paradigm, there ideally should be no distinction between management and research (Johnson et al. 2002; B. Campbell, J. Sayer, P. Frost, S. Vermeulen, M. Ruiz Perez, A. Cunningham, R. Prabhu, S. Waddington, and E. Chuma, unpublished manuscript). Traditional mechanistic approaches to natural resource management in which 'technological problems' were identified by 'expert scientists' and then fixed with 'technological solutions' are simply ineffective (Lewis 1997, Pahl-Wostl 2002, Pahl-Wostl and Hare 2004). Approaches need to allow all stakeholders to collectively and holistically generate an understanding of the complexity of the social, technological, economic, environmental, political system they are working within to jointly identify problems and to build trust as the basis for decision making and collaborative action (Pahl-Wostl and Hare 2004). This type of stakeholder interaction is fundamental to any natural resource management approach that acknowledges complexity, and that aims to effectively integrate and serve the needs of the natural resource system and the needs of the stakeholders who depend on that natural resource system (Johnson et al. 2002). However, the effective implementation of this type of stakeholder interaction in natural resource management in South Africa still faces a number of challenges.

\section{Challenges faced}

Effective stakeholder interaction is vital because local communities or targeted populations are often the center of involvement in ICT, TP, and NRM. Unfortunately, this interaction sometimes does not occur effectively in the ICT for development domain. For example, the ICT professional stakeholders usually neglect to understand that nonprofessional stakeholders are not just a source for testing a product or service, but they can provide valuable input that leads to localized innovative ideas that could have been overlooked by ICTD professional stakeholders (Schaffers et al. 2007). Other times some stakeholders lack the skills and knowledge to understand the requirements and implementation of ICTs in targeted environments. To compound this problem, the technical nature of ICTs introduces a language barrier. Also, because technological interventions are developed in relative isolation from their target systems because of practical constraints, divergent expectations tend to appear at a much earlier stage in the ICTD process, as compared to other multistakeholder projects. Different stakeholders evolve different ideas as to the purpose, implementation and characteristics of the envisioned technology, despite extensive consultation with multiple stakeholders in the early phases of a project.
When implementing ICTD, compromises need to be made. Most of these compromises stem from conflicting objectives and values among the stakeholders involved (Pade et al. 2010). For example, the goal of private organizations is to expand their ICT services market, e.g. to rural areas; the goal of government is to ensure a social, or political, benefit is accrued; the goal of academia may be to provide research opportunities; and the goal of the local community is to eradicate poverty and low standards of living, and to do so in a short period of time. However, if stakeholders cannot engage in key decisions that support and direct an ICTD project, such a project can end up being irrelevant in enabling development activities. In the worst case scenario, the implementation of ICTD projects may actually have more harmful effects in the targeted community (Gomez and Hunt 1999, Buré 2007). For example, one of the authors observed the following in their participation in ICTD project in South Africa: a lack of sensitivity to the culture and traditional communication values can negatively influence the indigenous identity of a community, divisions are created within communities based on who can or cannot use ICT services available, and also like any failed socioeconomic development initiative those that do not make a difference to people's lives can be disheartening psychologically.

For the town planning discipline, complexity is almost guaranteed by the multiplicity in cultures, meanings, communication styles, knowledge, and development goals that it needs to consider (Hillier and Healey 2008). Previous experiences of stakeholder interaction showed that some forms of stakeholder interaction can perpetuate colonialist power and knowledge structures (Sillitoe et al. 2002, Porter 2010), strengthening the Euro-American viewpoint in planning while ignoring other forms of knowledge or knowing (Sandercock 1998). Not all types of stakeholder interaction are equal or beneficial for the public (Arnstein 1969, Sandercock 1998). Discrepancies in power relations remain obvious (Wright and Nelson 1995, Hague and Jenkins 2005) or do not change at all (Hague and Jenkins 2005).

The existence of formal stakeholder interaction in South African TP legislation does not necessarily guarantee in-depth and quality stakeholder interaction. In certain cases, politicians, bureaucrats, planners, and researchers hinder stakeholder interaction objectives with their concern for predetermined standards, targets, time-frames and economic imperatives, shying away from the potential unexpected outcomes that can result from stakeholder interaction (Mahjabeen et al. 2009). Another major challenge is managing the complex input from other professions, i.e., geologists, sociologists, civil engineers, environmental managers, and municipal officials, with those of other nonprofessional stakeholders (Grosskurth and Rotmans 2005). To reach consensus between all parties is a fragmented, costly, and timeconsuming exercise and partly the reason why politicians, 
bureaucrats, planners, and researchers sometimes view participation unfavorably.

A key challenge for not only NRM, but also ICT and TP, is to identify the 'right' stakeholders, so that management decisions fairly reflect and integrate the full diversity of the system with which they are dealing (Lotz-Sisitka and Burt 2006). Stakeholders that directly depend on and use natural resources are frequently not the individuals who are chosen to represent the needs of the local community; it is often traditional leaders, or other wealthier and politically connected individuals who are invited to participate (Shackleton et al. 2002, Manning and Sealy 2005, Holmes-Watts and Watts 2008). Not only are these wealthier individuals likely to have different perspectives and needs than those in the community who are less well off, this approach to representivity erroneously ignores the heterogeneity of communities and the power dynamics involved in the different social institutions that different individuals rely on to stake their claims to resources (Leach et al. 1999). In addition, inclusivity is broader than representivity: inclusivity includes participants' access to the process itself, which is affected by how the process is conducted, how technical the content is, and the language through which the process is run (Sansom-Sherwill 2006). Nominal attendance of the rural poor is frequently counted as participation in decision making (Holmes-Watts and Watts 2008), when in reality, their needs and values have not even been voiced, let alone affected resource use decisions.

In South Africa, the capacity to stake a claim to a resource, or to effectively express particular needs, values, and perspectives, is in part determined by the power imbalances that are a legacy of the past. Participatory processes can easily entrench these power imbalances if they are not explicitly acknowledged and realistically dealt with in terms of negotiating skills, representation, language, resources available for preparation, e.g., power to consult a lawyer, and understand resource-use and access rights, prior to the participatory activity, and resources available for postparticipation follow up, e.g., power to contest negotiated decisions through other means (Leach et al. 1999, Johnson et al. 2002, Sansom-Sherwill 2006). Different stakeholders have different capacities to participate in different types of processes and spaces. Historically disadvantaged individuals, who had previously been excluded from natural resource management decision making in South Africa, are frequently further disempowered by the types of participatory approaches that are used.

Natural resource management decision making is often still rooted in a technocratic mechanistic approach, where technical ecological considerations dominate, and social/economic considerations are marginalized (Sansom-Sherwill 2006). The practitioners who are tasked with organizing and running participatory processes, primarily protected area managers, environmental scientists, private sector consultants, or officials from government departments, often view participatory processes as merely a means to persuade local stakeholders to support and legitimize a predetermined end that has already been decided upon by themselves, or other 'experts' (Sansom-Sherwill 2006, Holmes-Watts and Watts 2008). Practitioners are rarely given the opportunity to interrogate these perceptions, and many still lack the training, experience, and skills necessary to facilitate a participatory rather than a consultative process (Arnstein 1969, HolmesWatts and Watts 2008), that is, a process that facilitates social learning and dialogue among all stakeholders, creates the space for relationship and trust building, and provides incentives for stakeholders to engage in the collective decision making and action that is ultimately required for the sustainable use and management of complex natural resource systems.

In summary, the exploration of stakeholder interaction in the three disciplines revealed that some common challenges exist for applied researchers in these disciplines. Considering these challenges, it is evident that there is a degree of stakeholder interaction, but in many cases, it is largely ineffective. In addition, it was discovered that the three disciplines talk about the same things, but using substantially different language, terminology, and jargon. The commonalities can be allocated to two broad themes: (1) the existence of diverse perspectives, values, and goals, and (2) power dynamics (Table 1).

\section{Adaptive solutions}

Considering the mutual challenges experienced by ICTD, TP, and NRM, it seems that stakeholder interaction in all three disciplines exhibit characteristics of complex systems, such as having multiple perspectives, continuously changing dynamics, and unexpected outcomes. Further discussion among the authors also revealed that applied research in the three disciplines developed, perhaps in isolation, relatively similar adaptive research solutions to deal with the mentioned complexities, with exception to discipline-specific adaptations. Examples of such adaptive research solutions in South Africa include the Living Labs concept, sense of place research (SoP) conducted at the North-West University, and Strategic Adaptive Management (SAM); though these mentioned are not necessarily the only existing examples. As the purpose of this paper is not to give a detailed description of each of these adaptive research solutions, it will only elucidate certain characteristics of each that have a close connection to the discussion of this paper.

Originating from the ICTD discipline, a Living Lab exists as "collaborations of public-private-civic partnerships in which stakeholders co-create new products, services, businesses and technologies in real life environments and virtual networks in multi-contextual spheres" (Schumacher and Niitamo 2008:2). It is a user-centric approach that provides a platform to support 
Table 1. Commonalities in the three focus areas.

\begin{tabular}{|c|c|}
\hline Themes & Description \\
\hline $\begin{array}{l}\text { Diverse perspectives, } \\
\text { values, and goals }\end{array}$ & $\begin{array}{l}\text { - Results from the need to include multiple stakeholders who possess their own interests, perceptions, goals and } \\
\text { objectives and this often results in conflict and misunderstanding, which have to be accommodated to make } \\
\text { progress. } \\
\text { - The stakeholders comprise private sector involvement, government, academia, professionals from different } \\
\text { disciplines, and nongovernmental organizations. } \\
\text { - Leads to a major gap in understanding between the different stakeholders. }\end{array}$ \\
\hline Power dynamics & $\begin{array}{l}\text { - Results from different levels in understanding because of educational differences. } \\
\text { - Instead of participating in the process, the less powerful stakeholders, but often the most affected communities, } \\
\text { are only informed about what will be done without having any real understanding or say in the project, or } \\
\text { sometimes only have the right to approve predetermined facts. } \\
\text { - The group leading the participatory approach has the power to decide who gets involved, and to which extent, } \\
\text { thereby leaving the affected with only minor influence on their participation. It disempowers individuals further, } \\
\text { resulting in an increase in power imbalances, leaving the concerns of the affected to be neglected. }\end{array}$ \\
\hline
\end{tabular}

multistakeholder collaborations in an effort to apply essential research in communities and organizations. According to Mulder et al. (2008:8), the importance of the living lab is "the focus on user involvement and user experience in all steps of this process with a strong connection between design and understanding of real life behavior." Therefore, a Living Lab aims to explore how a product, initiative, or service is used, including its meaning in different social contexts. The key is cocreation supported by feedback and evaluation, in contrast to typical research methodologies in which a researcher, in academia, government, or industry, develops a product or service, with limited input and feedback (continuously) from end-users (local beneficiaries or environments) in the research process. The Living Lab concept is fairly new in South Africa, and has only been adopted by ICT for development projects, which have formed a network called Living Labs in Southern Africa. Such a network exists to share LL methodologies and tools to support innovative research in the African context.

The sense of place (SoP) research in TP (Puren et al. 2006, 2010, Jordaan et al. 2009) showed some similarities to the Living Labs concept. A recent research project on the farm Kromdraai, Vredefort Dome World Heritage Site in South Africa, focused on including stakeholders initially and continuously through the whole project (Puren et al. 2010). The researchers found that existing site-specific development frameworks revealed limited stakeholder interaction in the development of such frameworks. Furthermore, the depth of stakeholder interaction, when purely guided by TP legislation, was insufficient for creating context-sensitive and meaningful environments.

The aims of the SoP research were therefore to explore relational dimensions between people and a natural rural landscape; to implement a participatory approach to obtain insight into different relational dimensions; and to concretize socio-affective relational dimensions into the site planning guidelines. The research revealed that the stakeholders experienced Kromdraai as an area where they felt content, a sense of escape, curious, hopeful, spirituality, and safety. Stakeholders were asked to create visual presentations of how future development on the site can reflect their experiences. These presentations were then finally used as a basis for the final site plan and design guidelines for Kromdraai.

These stakeholder experiences and how they translate into site planning and design guidelines is usually not possible to achieve if the stakeholder interaction guidelines of TP legislation are slavishly followed. This seems to indicate that TP practice is not yet suitably adapted to the complexities of stakeholder indication. Compared to this, the experience from the Kromdraai project revealed that both participants and the researcher-practitioner experienced added value from interacting with each other, revealing thick descriptions that guided the site planning process, while still being able to proceed with the normal town planning procedures with minimum conflict between the various stakeholders (Puren et al. 2010).

Last, in terms of NRM, Strategic Adaptive Management (SAM) is a framework for planning, decision making, implementation, monitoring, and review that, so far, has been applied to natural resource management in the contexts of: (i) protected areas (SANParks has officially adopted SAM as their management approach) and; (ii) integrated water resource management, most practically and explicitly in work with the Inkomati Catchment Management Agency. The SAM framework was designed explicitly to deal with managing complex social-ecological systems (Rogers and Bestbier 1997), and its components are practiced as iterative cycles. SAM is essentially based on the principles of:

- Focusing on the future: management objectives and decisions are not based on trying to solve the problems 
Table 2. Some attributes of complex systems in terms of adaptive solutions.

\begin{tabular}{lllll}
\hline \hline & ICTD & TP & NRM \\
\cline { 2 - 3 } \cline { 4 - 5 } & Living Lab & SoP & SAM \\
\hline Attribute of complex system: & &
\end{tabular}

Attribute of complex system:

$\begin{array}{llll}\begin{array}{l}\text { Multiple valid } \\ \text { perspectives }\end{array} & \begin{array}{l}\text { All actors in the innovative process } \\ \text { have equal participation opportunity, }\end{array} & \begin{array}{l}\text { Various stakeholders are involved } \\ \text { from different disciplines and sectors }\end{array} & \begin{array}{l}\text { Decisions and actions are based on developing a } \\ \text { shared rationality between and acknowledgment of }\end{array} \\ & \text { including academia, government, } & \text { (public, private, and academic). } & \text { multiple stakeholders as part of the decision making } \\ \text { industry, communities, and users. } & & \text { context. }\end{array}$

Emergence Continuous interaction between various stakeholders and inherent feedback opportunities allow unpredicted elements or opportunities to emerge, despite not being planned.

Sensitivity to initial Living Labs attempt to capture interconditions (the holistic relations between different contexts context of the system in real-life. Initial and continuous at initiation) engagement with stakeholders enables interweaving of initial conditions from the start of the project.

Feedback loops

\begin{abstract}
Living Labs provide continuous feedback throughout the research process between end-users and researchers. Infrastructures and methodologies for evaluation are used by all actors.
\end{abstract}

\begin{abstract}
One aim of SoP is to develop evidence-based knowledge. Ideas that were not known before the evidence was gathered have the possibility to emerge without prior knowledge.
\end{abstract}

SoP is focused on strengthening contextual lived-in conditions and experiences of places through development. Rather than force alien development concepts onto a location, it uses in situ place experiences to form a unique development concept.

Interactions between various stakeholders are continuous and create checks and balances between the goals and expectations of stakeholders, acting as feedback loops.

SoP acknowledges that each development project and each site to be developed is unique. A certain degree of uncertainty exist because of this uniqueness and because the range of stakeholders differ in each case.
Change and uncertainty are inherent; complex systems are ultimately not predictable
Living labs specifically focus on creating solutions for real life contexts. Such real life contexts are inherently unpredictable and subject to change. Living Labs therefore acknowledge the existence of change and uncertainty in research.
The adaptive planning process encourages and seeks to facilitate the emergence of novel and innovative ideas from the interactions of stakeholders.

SAM embraces the idea of exploring the initial conditions before conceiving any management interventions to produce contextually grounded management solutions.
SAM creates desirable feedbacks in the management process at a number of levels over a number of time scales (adaptive decision making and action - operational level feedbacks; monitoring of outputs and outcomes of actions operational/strategic level feedbacks; review of vision and values, and deep loop learning paradigmatic feedbacks).

SAM is future-focused. It is about being adaptable, including monitoring outputs and outcomes of decisions and actions; reviewing outputs/outcomes against what was expected, what actions were actually implemented, how unforeseen events affected what happened, and how the outputs/ outcomes sit with perceived vision and values.

ICTD = Information and Communication Technology for Development

$\mathrm{TP}=$ Town Planning

NRM = Natural Resource Management

Sop $=$ Sense of Place research

SAM $=$ Strategic Adaptive Management

of today, but are based on a shared vision of a desired future and some initial ideas of how we might get there;

- Learning-by-doing, social learning, and making learning (single-, double-, and triple-loop learning) explicit;

- Participatory decision making, based on the initial, and regularly revisited, development of a 'shared rationality' between all stakeholders, e.g., resource users, management practitioners, government officials, NGOs, academics/so-called 'experts'). Decisions are made through consensus.
- Adaptability of actions, decisions, shared values, etc. over appropriate time frames, and based on explicit processes of learning and review.

One key objective of the whole process is to encourage decisions to emerge from the interactions of the participants, as opposed to the many consultative approaches that involve presenting a predetermined decision to stakeholders.

Considering the characteristics of the different applied research solutions to complexity issues, it is necessary to once again refer back to complexity. According to complexity 
theory, complex systems have "multiple interacting parts that exhibit non-linear behavior leading to unpredictability and being made up of nested systems that are open and mutually affecting with each level exhibiting patterns that emerge out of the interactions of the parts" (Apgar et al. 2009:3). Table 2 summarizes the complexity characteristics that emerge from applied research in ICTD, TP, and NRM and how the adaptive solutions attempt to address the same complexity issues.

From Table 2, the argument for viewing stakeholder interaction in applied research in ICTD, TP, and NRM as complex systems seems like a real possibility. Despite the disciplinary differences, applied research in all areas exhibit elements of a complex system, and each discipline attempts to address these elements with a similar adaptive approach. Consequently, the authors propose that stakeholder interaction in applied research is more than just an action, a process, or a network, but actually has some characteristics that align it more to complexity theory.

\section{CONCLUSION AND THE WAY FORWARD}

Common challenges of stakeholder interaction in applied research in the discipline of ICTD, TP, and NRM have been elucidated. These challenges illustrated diverse perspectives, values, and goals. In addition, power dynamics between various stakeholders posed a very real challenge for all the disciplines. Each discipline developed approaches for dealing with these challenges, namely Living Labs, SoP research, and SAM. Despite using fundamentally different disciplinary language, each of these approaches highlight overlapping concepts that show some link to complexity theory. This could indicate on a broader level that stakeholder interaction in applied research adheres to some of the principles of complexity theory. Each of the three disciplines developed contextually embedded methodologies to acknowledge and address the complexity inherent in stakeholder interaction.

However, as transdisciplinary projects become more prevalent, the contextual language and terminology changes from being a tool to deal with complexity in a complex system to being a barrier between stakeholders in different disciplines. We propose that transdisciplinary stakeholder interaction should also be approached from a complexity viewpoint, as opposed to choosing a single methodology from a particular discipline, and its implicitly bound language, by examining transdisciplinary stakeholder interaction from a shared perspective.

However, even though the different approaches may to some extent address the mentioned challenges, one has to acknowledge possible weaknesses. One of these is that the Living Labs, SoP research, and SAM approaches are all time consuming because of the large amount of stakeholders that must be identified, contacted, briefed, allowed to participate, included in negotiations, and be given feedback. Not only is this time consuming, it also presupposes relatively stable and continuous sources of funding for such an exercise. Furthermore, these adaptive approaches do not present the researchers and developers with immediate outcomes or solutions to specific problems. They are process-oriented and not product-oriented and can, therefore, create some confusion among stakeholders with regard to what can be considered a success. A different expectation needs to be founded with regard to stakeholder interaction because these adaptive approaches propose to cocreate solutions that are more adaptive to potential issues in the long term.

The way forward seems to indicate that complexity theory may provide a common language between different disciplines. As complexity theory and language have the ability to break down the current misalignment due to differing terminology, the possibility becomes greater to address the challenges of stakeholder interaction by means of transdisciplinary research. Therefore, there is a clear need for future research on stakeholder interaction in applied research as part of broader complexity theory.

Responses to this article can be read online at: http://www.ecologyandsociety.org/issues/responses. php/5405

\section{Acknowledgments:}

We would like to acknowledge the critical feedback and review provided by members of the Akili Scientists Group and sponsorship by the National Research Foundation. Thank you for your guidance and opportunity to conduct this research and collaborate with our peers from different disciplines and institutions.

\section{LITERATURE CITED}

Adam, M., M. Carrier, and T. Wilholt. 2006. How to serve the customer and still be truthful: methodological characteristics of applied research. Science and Public Policy 33(6):435-444. http://dx.doi.org/10.3152/147154306781778849

Alexander, E. 2008. Public participation in planning - a multidimensional model: the case of Israel. Planning Theory \& Practice 9(1):57-80. http://dx.doi.org/10.1080/14649350701843853

Apgar, J. M., A. Argumedo, and W. Allen. 2009. Building transdisciplinarity for managing complexity: lessons from indigenous practice. International Journal of Interdisciplinary Social Sciences 4(5):255-270.

Arnstein, S. R. 1969. A ladder of citizen participation. Journal of the American Institute of Planners 35(4):216-224. http:// dx.doi.org/10.1080/01944366608977225 
Bammer, G. 2005. Integration and implementation sciences: building a new specialization. Ecology and Society 10(2): 6. [online] URL: http://www.ecologyandsociety.org/vol10/iss2/ art6/

Booher, D. E., and J. E Innes. 2002. Network power in collaborative planning. Journal of Planning Education and Research 21:221-236. http://dx.doi.org/10.1177/0739456X0202100301

Brown, L. D., G. Bammer, S. Batliwala, and F. Kunreuther. 2003. Framing practice-research engagement for democratizing knowledge. Action Research 1(1):81-102. http://dx.doi. org/10.1177/14767503030011006

Buré, C. 2007. Grounding gender evaluation methodology for telecentres: the experiences of Ecuador and the Philippines. Telecentre.Org, International Development Research Centre (IDRC), Ottawa, Ontario, Canada.

Chettiparamb, A. 2007. Re-conceptualizing public participation in planning: a view through autopoiesis. Planning Theory 6 (3):263-281. http://dx.doi.org/10.1177/1473095207082034

Cooke, B., and U. Kothari, editors. 2001. Participation: the new tyranny? Zed Books, London, UK.

Council for Scientific and Industrial Research (CSIR). 2000. Guidelines for human settlement planning and design. CSIR Building and Construction Technology, Pretoria, South Africa.

Davidoff, P. 1965. Advocacy and pluralism in planning. Journal of the American Institute of Planners 31(4):331-338. http://dx.doi.org/10.1080/01944366508978187

Eriksson, M., V.-P. Niitamo, and S. Kulkki. 2005. State-ofthe-art in utilizing Living Labs approach to user-centric ICT innovation: a European approach. Vinnova, Stockholm, Sweden. [online] URL: http://www.vinnova.se/upload/ dokument/Verksamhet/TITA/Stateoftheart LivingLabs Eriksson2005. pdf

Friedmann, J. 1973. Retracking America: a theory of transactive planning. Doubleday, New York, New York, USA.

Gerster, R., and S. Zimmerman. 2003. Information and communication technologies and poverty reduction in subSaharan Africa. Gerster Consulting, Richterswil, Switzerland.

Gomez, R., and P. Hunt. 1999. Telecentre evaluation: a global perspective. International Development Research Centre (IDRC), Ottawa, Ontario, Canada.

Grosskurth, J., and J. Rotmans. 2005. The scene model: getting a grip on sustainable development in policy making. Environment, Development and Sustainability 7:135-51. http://dx.doi.org/10.1007/s10668-003-4810-0
Hague, C., and P. Jenkins, editors. 2005. Place identity, participation and planning. Routledge, Oxfordshire, UK.

Healey, P. 1997. Collaborative planning: shaping places in fragmented societies. UBC Press, Vancouver, British Columbia, Canada.

Hedrick, T. E., L. Bickman, and D. J. Rog. 1993. Applied research design: a practical guide. Sage, Newbury Park, California, USA.

Heeks, R. 1999. Information and communication technologies, poverty and development. Development Informatics, Working Paper Series, Paper No. 5. Institute for Development Policy and Management, University of Manchester, Manchester, UK.

Heeks, R. 2009. The ICT4D 2.0 manifesto: where next for ICTs and international development? Institute for Development Policy and Management, University of Manchester, Manchester, UK.

Hillier, J., and P. Healey, editors. 2008. Contemporary movements in planning theory: critical essays in planning theory: Volume 3. Ashgate, Surrey, UK.

Holmes-Watts, T., and S. Watts. 2008. Legal frameworks for and the practice of participatory natural resource management in South Africa. Forest Policy and Economics 10:435-443. http://dx.doi.org/10.1016/j.forpol.2008.02.005

Johnson, N., H. M. Ravnborg, O. Westermann, and K. Probst. 2002. User participation in watershed management and research. Water Policy 3(6):507-520. http://dx.doi.org/10.1016/ S1366-7017(02)00014-4

Jordaan, T., K. Puren, and V. Roos. 2009. Exploring placemaking in the Vredefort Dome, South Africa: a mixed-method approach. Stads- en Streekbeplanning 55:3-15.

Lane, M. B. 2005. Public participation in planning: an intellectual history. Australian Geographer 36(3):283-299. http://dx.doi.org/10.1080/00049180500325694

Leach, M., R. Mearns, and I. Scoones. 1999. Environmental entitlements: dynamics and institutions in community-based natural resource management. World Development 27 (2):225-247. http://dx.doi.org/10.1016/S0305-750X(98)00141-7

Lewis, G. J. 1997. A cybernetic view of environmental management: the implications for business organisations. Business Strategy and the Environment 6:264-275. http://dx. doi.org/10.1002/(SICI)1099-0836(199711)6:5<264::AIDBSE122>3.0.CO;2-K

Loh, C. G. 2012. Four potential disconnects in the community planning process. Journal of Planning Education and Research 32(1):33-47. http://dx.doi.org/10.1177/0739456X11424161 
Lotz-Sisitka, H., and J. Burt. 2006. A critical review of participatory practice in Integrated Water Resource Management. Association for Water and Rural Development, Acornhoek, South Africa.

Mahjabeen, Z., K. K. Shrestha, and J. A. Dee. 2009. Rethinking community participation in urban planning: the role of disadvantaged groups in Sydney Metropolitan Strategy. Australasian Journal of Regional Studies 15(1):45-63.

Manning, N., and M. Sealy. 2005. Forum for integrated resource management (FIRM) in ephemeral basins: putting communities at the center of the basin management process. Physics and Chemistry of the Earth 30:886-893. http://dx.doi. org/10.1016/j.pce.2005.08.035

Max-Neef, M. A. 2005. Foundation of transdisciplinarity. Ecological Economics 53:5-16. http://dx.doi.org/10.1016/j. ecolecon.2005.01.014

Moodley, S. 2005. The promise of E-Development? A critical assessment of the state ICT for poverty reduction discourse in South Africa. Perspectives on Global Development and Technology 4(1):1-26. http://dx.doi.org/10.1163/1569150053888254

Mulder, I., W. Bohle, S. Boshomane, C. Morris, H. Tempelman, and D. Velthausz. 2008. Real world innovation in rural South Africa. The Electronic Journal for Virtual Organisations and Networks 10:8-20.

Pade, C., I. Siebörger, H. Thinyane, and L. Dalvit. 2010. The Siyakhula living lab: a holistic approach to rural development through ICT in rural South Africa. Pages 42-77 in J. Steyn, J.P. Van Belle, and E. V. Mansilla, editors. ICTs for Global Development and Sustainability. IGI Global, Hershey, Pennsylvania, USA.

Pahl-Wostl, C. 2002. Towards sustainability in the water sector-the importance of human actors and processes of social learning. Aquatic Sciences 64:394-411. http://dx.doi. org/10.1007/PL00012594

Pahl-Wostl, C. and M. Hare. 2004. Processes of social learning in integrated resources management. Journal of Community \& Applied Social Psychology 14:193-206. http://dx.doi. org/10.1002/casp.774

Pearce, J. 2010. Participation and democracy in the twentyfirst century city. Palgrave Macmillan, New York, New York, USA. http://dx.doi.org/10.1057/9780230277342

Porter, L. 2010. Unlearning the colonial cultures of planning. Ashgate, Surrey, UK.

Puren, K., H. Coetzee, and V. Roos. 2010. A hidden dimension in site planning: exploring affective experience as part of sense of place on the farm Kromdraai, Vredefort Dome World
Heritage Site, South Africa. Pages 1122-1132 in Proceedings of the World Academy of Science, Engineering and Technology Conference, on Academic Science Research, 28-30 June 2010, Paris, France. World Academy of Science, Engineering and Technology, Las Cruces, New Mexico, USA.

Puren, K., J. E. Drewes, and V. Roos. 2006. An exploration of sense of place as informative for spatial planning guidelines: a case study of the Vredefort Dome World Heritage Site, South Africa. International Journal of Human and Social Sciences 1(3):190-197.

Rogers, K. H., and R. X. Bestbier. 1997. Development of a protocol for the definition of the desired state of riverine systems in South Africa. Department of Environmental Affairs and Tourism, Pretoria, South Africa. [online] URL: http:// www.ngo.grida.no/soesa/nsoer/resource/wetland/abstract protocol. $\underline{\mathrm{htm}}$

Roloff, J. 2008. A life cycle model of multi-stakeholder networks. Business Ethics: A European Review 17 (3):311-325. http://dx.doi.org/10.1111/j.1467-8608.2008.00537. $\underline{\mathrm{x}}$

Samson-Sherwill, T. 2006. Public participation in integrated water resource management in South Africa: current, potential and suggested future approaches. Thesis, University of the Witwatersrand, Johannesburg, South Africa.

Sandercock, L. 1998. Towards cosmopolis: planning for multicultural cities. John Wiley and Sons, Chichester, UK.

Schaffers, H., M. G. Cordoba, P. Hongisto, T. Kallai, C. Merz, and J. van Rensburg. 2007. Exploring business models for open innovation in rural living labs. Proceedings of the 13th International Conference on Concurrent Enterprising, 4-6 June 2007, Sophia-Antipolis, France. The Institute of Electrical and Electronics Engineers, New York, New York, USA.

Schumacher, J., and V.-P. Niitano, editor. 2008. European Living Labs - a new approach for human centric regional innovation. Wissenschaftlicher Verlag Berlin, Berlin, Germany.

Shackleton, S., B. Campbell, E. Wollenberg, and D. Edmunds. 2002. Devolution and community based natural resource management: creating space for local people to participate and benefit? Natural Resource Perspectives 76.

Sillitoe, P., A. Bicker, and J. Pottier, editors. 2002. Participating in development: approaches to indigenous knowledge. Routledge, London, UK.

Ulanowicz, R. W., R. E. Ulanowicz, and S. A. Kaufman. 2009. A third window: natural life beyond Newton and Darwin. Templeton Press, West Conshohocken, Pennsylvania, USA. 
Umemoto, K., and H. Igarashi. 2009. Deliberative planning in a multicultural milieu. Journal of Planning Education and Research 29:39-53. http://dx.doi.org/10.1177/0739456X09338160

United States Agency for International Development (USAID). 2003. Future directions in agriculture and information and communication technologies (ICTs) at USAID. USAID, Washington, D.C, USA.

Woodhill, J. 2009. Institutional innovation and stakeholder engagement: linking transition management in the North with development in the global South. Pages 273-291 in K. J. Poppe, C. Termeer, and M. Slingerland, editors. Transitions towards sustainable agriculture and food chains in peri-urban areas. Wageningen Academic Publishers, Wageningen, The Netherlands.

Wright, S. and N. Nelson. 1995. Participatory research and participant observation: two incompatible approaches. Pages 43-59 in N. Nelson, and S. Wright, editors. Power and participatory development: theory and practice. IT Publications, London. UK. 